\title{
MÍMESIS Y VOLUNTAD DE PODER
}

\author{
DANIEL RiBero FuQueN* \\ doi:10.11144/Javeriana.uph31-62.rmvp
}

\begin{abstract}
EN LA HISTORIA DE LA FILOSOFÍA HAY CIERTOS AUTORES a quienes se les reconoce la influencia de su pensamiento en la cultura de Occidente. Una de esas grandes personalidades que jalona nuestro destino espiritual es Federico Nietzsche. Sus escritos representan una radical crítica de la religión, la filosofía, la ciencia, la moral, y la negación de todas las tradiciones. Su demoledora crítica es fuente continua de inspiración para sucesivas interpretaciones de la cultura, al punto que su muy conocida proclama de la muerte de Dios, hace eco en otros autores que hablan de la muerte de la metafísica, de la muerte de la verdad, la muerte de la modernidad, la muerte de la religión, incluso de la muerte del hombre.
\end{abstract}

Pero Nietzsche no solo se enfrenta de manera crítica al pasado, sino que invierte los valores occidentales y proclama una oscura profecía, con voluntad de futuro, como mensajero del nihilismo. Caracteriza una nueva comprensión del universo con sus imágenes, figuras, símbolos y metáforas del Último hombre, del Superhombre, del Eterno retorno.... En contraste con la mayoría de los autores filosóficos, todos sus libros están escritos al estilo de confesiones que seducen las almas de sus lectores porque exponen la suya. De ahí que a comienzos del siglo XX las interpretaciones y comentarios ensalzaran su pensamiento, su genialidad, como sagaz descubridor de todo lo mórbido y putrefacto de nuestra cultura. Con el tiempo, las interpretaciones han ido tomando distancia de la figura legendaria haciéndose más rigurosas, más ajustadas a la realidad, más críticas. Esta labor de sopesar el legado de sus antecesores es lo que todo pensador debe emprender si en algo quiere colaborar para dilucidar su actualidad.

\footnotetext{
*Pontificia Universidad Javeriana, Bogotá, Colombia.

Para citar este artículo: Ribero Fuquen, D. (2014). Mímesis y Voluntad de poder. Universitas Philosophica, 31(62), 241-254. ISSN 0120-5323; ISSN en línea 2346-2426; doi:10.11144/ Javeriana.uph31-62.rmpv
} 
Este escrito analiza lo que muchos estudiosos juzgan como una de las categorías más importantes de Nietzsche: la Voluntad de poder, y tiene el propósito de revelar que ella suministra una justificación intelectual de la conducta más contraproducente exigida por las fases agudas del proceso mimético. En otras palabras, es una lectura del pensamiento de Nietzsche con las categorías filosóficas de la teoría mimética del filósofo francés René Girard. En aras de una mejor comprensión de la cuestión plateada a lo largo de estas páginas, primero haré una breve presentación de la teoría mimética y, segundo, explicaré la Voluntad de poder mostrando cómo en ella aparecen las distintas fases del proceso de mediación

\section{La teoría mimética}

GiRARD LLEVA HASTA SUS Últimas CONSECUENCIAS una afirmación de la Poética de Aristóteles: "El hombre se diferencia de los demás animales en que es el ser que más tiende a imitar" (Aristóteles: 48b, 6-7), y devuelve al concepto de imitación o mímesis su significado más amplio, tanto antropológico como social. Esto lo obliga a repensar la noción de deseo mostrando cómo este surge siempre de la imitación del deseo de otro, al que se le toma como modelo. Dado que ambos desean obtener el mismo objeto, la imitación tiende a volverse una rivalidad creciente entre el modelo y el sujeto deseante. Este proceso sucede en dos fases: la mímesis de apropiación o adquisitiva y la mímesis del antagonista.

\section{A) Mímesis de apropiación}

"El INICIO, LA ETAPA SEDUCTIVA DEL DESEO, está marcada por la fascinación con los modelos. Esta etapa es de rivalidad aunque no necesariamente violenta" (Grande, 2009: 107). Pero si la imitación es demasiado perfecta, si el seguidor amenaza con superar al modelo, entonces el modelo cambia sistemáticamente de actitud y empieza a mostrarse desconfiado, celoso, hostil. Hará todo lo que pueda para humillar al seguidor y desanimarlo. Como dice Grande: "La transición de ser amigos competitivos a rivales se presenta como resultado del deseo. El deseo es la fuerza generadora detrás de la violencia, la serpiente que convierte amigos y amantes en rivales" (Grande, 2009: 86).

\footnotetext{
1 "The initial, seductive stages of desire are marked by the fascination with models. This stage is rivalistic but not necessarily violent". La traducción es mía.

2 "The transition from being competitive friends to rivals comes as the result of desire. Desire is the generative force behind violence, the snake that turns friends and lovers into rivals". La traducción es mía.
} 
El seguidor no tiene más culpa que la de ser el mejor de los discípulos. Admira y respeta al modelo; en efecto, si no fuera así no lo habría tomado como modelo. Sin embargo, le falta esa distancia que le permitiría poner lo que le ocurre en perspectiva, pues no reconoce en el comportamiento del modelo los signos de la rivalidad. Y eso es más difícil todavía, dado que el modelo se empeña en reforzar esa ceguera, trata de disimular cuanto puede la verdadera razón de su hostilidad. Esta es la condición mecánica de la imitación primaria que predispone al seguidor a desconocer el carácter automático de la rivalidad que le opone al modelo (Cfr. Girard, 1982: 328). Se entra, entonces, en un círculo vicioso en el que, por una parte, el seguidor se siente injustamente tratado y ferozmente perseguido por el modelo; por otra, imita cada vez más al modelo y se pone de su lado preguntándose si el modelo no tendrá razones justificadas para rehusarle el objeto. Para el seguidor, el modelo posee una autosuficiencia y una omnisciencia que él también desea tener.

El modelo le cierra obstinadamente el paso hacia el objeto porque es su posesión lo que establece la diferencia entre la insuficiencia y la autosuficiencia. Con lo cual, el objeto del deseo se presenta a la vez como prohibido y deseable, pues es ciertamente prohibido por aquel que lo designa como deseable deseándolo él mismo. En este momento, el objeto es más deseado que nunca. El objeto aparece transfigurado como lo más valioso, lo más real que puede haber. La rivalidad mimética, que aviva las ambiciones, le ha conferido al objeto una dimensión ontológica o metafísica (Cfr. Girard, 1982: 334) que antes no tenía; su valor crece en proporción a la resistencia que implica su adquisición.

\section{B) Mímesis del antagonista}

LA MÍMESIS ES MÁS FUERTE QUE NUNCA, pero ya no puede ejercerse a nivel del objeto, pues éste como tal ha dejado de existir debido al valor agregado engendrado. El hecho de rivalizar por él lo ha transfigurado en un objeto que no tiene ninguna realidad tangible, pero que lo hace parecer más real que cualquier objeto real. Así, si no hay objeto, tampoco hay mímesis de apropiación en el sentido definido, y el único terreno de aplicación posible para la mímesis son los propios sujetos. Ya no se rivaliza por el objeto tangible, sino por quién se queda con el objeto, es decir, por quién obtiene más valor por el hecho de ganar. En esta rivalidad por el prestigio, la obsesión de los contrincantes consiste en derrotar al contrario y no en conseguir el objeto, que pasa a constituirse en un simple pretexto para la exasperación del conflicto. A lo anterior Kirwan lo llama "metaphysical mimesis" (Kirwan, 2005: 48), lo cual significa que cuanto más se exasperan las rivalidades, más tienden los sujetos a olvidarse de los objetos que las causan en el comienzo y se sienten más fascinados los unos por los otros porque, al igual que el 
objeto, el valor del modelo crece en proporción a la dificultad que implica imitarlo. Cada rival se convierte para el otro en el modelo-obstáculo adorable y odiable, al que necesita abatir y absorber. Entonces, ya no hay más que antagonistas y el conflicto se convierte en rivalidad pura o en mímesis del antagonista.

En el mundo competitivo de los dobles no existen relaciones neutras o estables. Solo hay dominantes y dominados. Cada vez que una parte domina o piensa dominar a su rival, el sujeto se cree el centro de un campo perceptivo que, por el contrario, parece estructurarse en torno al rival en el momento en que este tiene la preeminencia. Por su parte, el otro prevalece cada vez más y por más tiempo. Así, este tiende a ir suplantando progresivamente a aquel, de tal manera que la relación entre los rivales se parece a un balancín en continuo movimiento en el que cuando uno sube el otro baja.

Adicional a esta dinámica, hay una lógica propia del desconocimiento, de la exasperación y agravación, suscitada por las primeras interferencias miméticas, que domina el deseo y las interpretaciones del deseo (Cfr. Girard, 1982: 327). Los que se entregan a los fenómenos imitativos, de violencia o de rivalidades pasionales, realizan siempre los mismos gestos y no dejan de imitarse mutuamente, con lo que se transforma cada uno en un simulacro del otro. La rivalidad hace de cada uno de ellos el doble imitativo del otro. Pero, para que exista una relación mimética de dobles, se necesita un sujeto incapaz de interpretar correctamente el doble imperativo procedente del otro que le invita, en cuanto modelo, a imitarle, y en cuanto rival, a no imitarle.

Y aunque de hecho se trata del mismo deseo, este ya no cree en la trascendencia del modelo, pues tanto si el sujeto triunfa como si pierde en la consecución del objeto, siempre se dirige al fracaso. En ambos casos el sujeto se pone a buscar un nuevo modelo y un nuevo objeto guiado por el deseo. Si triunfa, aspira a una nueva resistencia insuperable a un objeto y a un modelo que no le decepcionen fácilmente; si fracasa, busca dar al deseo una última oportunidad tan pronto como se presente un nuevo modelo u objeto (Cfr. Girard, 1982: 336-340). La interpretación que siempre hará el sujeto será responsabilizar al objeto y al modelo de esta situación, pero nunca al carácter mimético del deseo. El deseo mismo es un callejón sin salida. $\mathrm{O}$, como lo expresa Grande, "hay algo orgánico en la rivalidad mimética; la contaminación es tan fuerte que la salida de los conflictos violentos parece requerir un cambio de corazón, un acto de perdón, con el fin de detener el ciclo de nunca acabar"3. (Grande, 2009: 87)

\footnotetext{
3 "There is something organic in mimetic rivalry; the contamination is so strong that the way out of violent conflicts seems to require a change of heart, an act of forgiveness in order to stop the never-ending cycle". La traducción es mía.
} 
Todo se refuerza en un proceso que Girard, relacionándolo con el double bind de Bateson (Cfr. Bateson, 1972: 201-227)4, denomina "feedback positivo" (Girard, 1982: 333) porque los movimientos van siempre en el mismo sentido y no dejan de ampliarse; es decir, el suceso " $a$ " desencadena el suceso " $b$ ", que a su vez desencadena otros sucesos, pero el último de ellos vuelve sobre el suceso " $a$ " y reacciona sobre él. De este modo, el sistema tiende al desbocamiento - runaway - que termina en su ruptura y completa destrucción.

El proceso de crisis mimética es literalmente la diferencia de roles que se invierte para disolverse y borrarse después, hasta dejar sitio a la violencia recíproca (inversión de funciones, parodias recíprocas, burlas insultantes, etcétera). "Si la imitación de otros, conduce inevitablemente a la rivalidad y el conflicto, y si todos los seres humanos actúan miméticamente, la humanidad en su conjunto parece estar condenada a un interminable ciclo de competencia y violencia. La supervivencia humana y la génesis y el desarrollo de la cultura son difíciles de concebir en esas condiciones" (Golsan, 2002: 29) pues, si en el grupo no se produce alguna resolución, podemos pensar que este se desintegra bajo el efecto de una violencia cada vez más intensa.

\section{La Voluntad de poder}

Quien haya leído los escritos de Nietzsche se habrá dado cuenta de la relevancia que tuvo el músico alemán Ricardo Wagner en la configuración de su pensamiento. La relación que Nietzsche mantuvo con Wagner va más allá de simples encuentros sociales, muestra de ello es la cantidad de obras que hacen referencia a él. Su libro El nacimiento de la tragedia en el espíritu de la música es un explícito homenaje a Wagner, por cuanto interpreta su drama musical como una obra de arte que se corresponde con la tragedia griega (Cfr. Fink, 1984: 19). Igualmente, en las Consideraciones intempestivas, Nietzsche no solo expone su concepción del genio, sino que ve confirmada su teoría en dos personas a quienes adoraba: Schopenhauer y Wagner (Cfr. Fink, 1984: 41). Posteriormente, su obra Humano, demasiado humano representa una ruptura, un desgarro profundo e irreparable: la separación interna de Wagner y el apartarse de Schopenhauer, y significa la despedida

\footnotetext{
${ }^{4}$ Véase también los otros artículos de esta obra, sobre todo: Minimal Requirements for a Theory of Schizophrenia, 1972, 244-270, y Double Bind, 1969, 271-278.

5 "If imitation of others leads inevitably to rivalry and conflict, and if all humans act mimetically, then humanity as a whole would appear to be doomed to an endless cycle of competition and violence. Human survival and the genesis and development of culture are difficult to conceive under these conditions". La traducción es mía.
} 
de los héroes de su juventud a los que había dedicado su mayor adoración, su ardiente entusiasmo (Cfr. Fink, 1984: 50). Nietzsche interpreta estos sucesos como el despertar del sueño romántico de su veneración a los héroes, como el distanciamiento de sus ídolos para llegar a ser él mismo. A estos escritos debemos agregar: El caso Wagner y Nietzsche contra Wagner.

La obsesión que sentía Nietzsche por Wagner, evidentemente, no era un simple entusiasmo juvenil rectificado cuando el pensador alcanzó la madurez sino que, como dice Girard, "Wagner es una gran parte de las obras, [pues] Nietzsche escribió a favor de Wagner, luego contra Wagner durante toda su vida, a veces directamente, alabándolo y atacándolo por su nombre, otras veces indirectamente. Cuando se aproxima el colapso final y aunque Wagner ya ha muerto, continúa siendo una figura que lo obsesiona, quizá más que nunca" (Girard, 1984: 74).

La historia de las relaciones de Nietzsche con Wagner no puede ignorarse aduciendo los tradicionales argumentos sobre la inconmensurabilidad entre la vida y las obras del autor, dada sus alusiones directas y al estilo casi confesional de sus escritos. Como veremos, esta relación corresponde perfectamente a las fases sucesivas del proceso mimético. Inicialmente, Wagner es el modelo explícitamente reconocido, la divinidad a la que se rinde abiertamente culto; después, se convierte en un obstáculo y en un rival sin dejar de ser un modelo, pues Wagner se está convirtiendo en el héroe cultural del pueblo alemán que impide a su discípulo llegar a la meta que se ha propuesto.

A fin de socavar el culto a Wagner, Nietzsche recurrió a muchas artimañas, como cuando sugirió al compositor francés Georges Bizet como un dios musical substituto, o cuando presenta el festival de Bayreuth como el monstruoso esfuerzo de Wagner para organizar su propio culto. Puede ser que Nietzsche no esté equivocado en sus apreciaciones, pero su libro Ecce Homo es exactamente lo mismo. Pretende que todo cuanto escribió sobre Wagner en el pasado, las alabanzas sobre ese falso ídolo no sean desechadas ni olvidadas sino, por el contrario, sean aplicadas a su verdadero merecedor, el propio Nietzsche (Cfr. Nietzsche, 1980: 101). Esta obra representa el esfuerzo de Nietzsche para organizar su propio culto, la única diferencia es que Wagner tiene adoradores reales, en tanto que Nietzsche solo se tiene a sí mismo.

Por obra de lo que ahora se le representa como una trampa diabólica, Nietzsche se da cuenta que consintió y fomentó el injusto triunfo del mediador; ahora se ve desposeído de su propio yo y trata cada vez más desesperadamente de llenar el vacío, no solo con Wagner, sino con cuanto 
modelo histórico o mitológico impresione su fantasía. Al final, esta reciprocidad mimética que se realiza a pesar de los esfuerzos mismos de Nietzsche por anularla, en el momento en que la respuesta ambivalente al modelo como obstáculo y al obstáculo como modelo cede lugar a la crisis de identidad y a la megalomanía, retorna a la primera relación en la que el modelo era abiertamente objeto de culto. Lo que está constantemente en juego entre Wagner y Nietzsche es la victoria y la derrota propia de una relación concreta de dobles de la estructura de antagonistas.

Aquí se podría argumentar que el deseo mediado puede tener influencia solo en los escritos de Nietzsche sobre Wagner, pero el resto de su filosofía quedaría sin ser afectada por la mímesis. Veamos qué tan cierto puede ser esto.

Al principio, Nietzsche usó la expresión Voluntad de poder únicamente para efectos de una desmitificación psicológica de actos atribuidos al altruismo y otros buenos sentimientos morales, es decir, a conductas secretamente motivadas por un miramiento extremo de la opinión de los demás. Consideró que la compasión era o bien una impudicia o bien mera hipocresía. Primeramente, dice que es mezquina; da un poco, tan solo un poco. "Yo no doy limosnas. No soy bastante pobre para eso" (Nietzsche, 1983: 33) dice Zaratustra. Pero no se trata simplemente de no dar, de no dar nada, sino justamente de dar más: de dar todo. Zaratustra da más que una limosna: cuando da, se da a sí mismo por completo, sin reservas.

Por esta razón, para Nietzsche, el camino al altruismo pasa por el del egoísmo: es necesario crear un mundo de riqueza interior si se quiere luego tener algo que compartir. Para dar es ineludible antes tener algo que dar. El individuo sano da por sobreabundancia, como una copa que necesita vaciarse, necesita darse. No da por remordimiento ni por culpa, no da por querer quedar bien con Dios o con los hombres, da porque necesita dar, su deseo más imperioso y fuerte es donarse a sí mismo. Por ello en Nietzsche existen dos formas de egoísmo: uno sano y sagrado que posibilita el tener algo que dar, otro pobre y hambriento que mira con envidia (Cfr. Fink, 1984: 87). Entonces, tanto la compasión como el altruismo tienen raíces en la Voluntad de poder. Walter Kaufmann, en su obra Nietzsche: filósofo, psicólogo, anticristo, observó que en esa fase Nietzsche "no exhortaba a desarrollar una Voluntad de poder ni hablaba de ella como algo glorioso" (Kaufmann, 1956: 159).

\footnotetext{
6 "He did not exhort people to develop a will to power, nor did he speak of it as anything glorious".
} 
Sin embargo, el Nietzsche posterior con frecuencia presenta la Voluntad de poder como la fuerza que mueve todo el universo. A decir de Heidegger, la convirtió en la base de un sistema metafísico y en la única virtud que se debe abrazar y desarrollar plenamente. El carácter distintivo de la Voluntad de poder consiste en ser una forma de energía que determina todo lo existente en cuanto tal pues, como dice Nietzsche, "en todos los lugares donde encontré seres vivos encontré voluntad de poder; e incluso en la voluntad del que sirve encontré voluntad de ser señor" (Nietzsche, 1983: 171). Sin embargo, esta voluntad se divide en dos variantes contrapuestas. La primera podría llamarse la auténtica Voluntad de poder; a la otra la llama a menudo Resentimiento; ambas solo pueden ser diferenciadas en términos de cantidad (Cfr. Girard, 1984: 81). Pero, la naturaleza conflictiva y competitiva de la Voluntad de poder convierte la diferencia cuantitativa en cualitativa.

Los individuos que poseen más voluntad vencen y sojuzgan a los que poseen menos, por lo cual los fuertes deben dominar a los débiles y los débiles deben experimentar amargo Resentimiento por su inferioridad. Los débiles harán todo cuanto puedan por escapar a las consecuencias de esa inferioridad y hasta negarán su realidad, aun sabiendo que en cualquier nuevo encuentro frente a frente quedarán nuevamente derrotados, de suerte que se ven condenados a apelar a medios tortuosos. Como son numerosos, pueden unirse para inventar religiones y filosofías que parezcan altruistas, pero cuya única finalidad es subvertir la natural jerarquía de la Voluntad de poder (Cfr. Fink, 1984: 92).

Frente a los nobles, los espíritus débiles, incapaces de amar la vida, no podían sentir más que Resentimiento. El esclavo que no puede abrazar la vida acaba odiándola y lamentándose de ella y, por extensión, odiando a los fuertes que representan un modo de vida del que el esclavo es incapaz. La debilidad del esclavo se convierte en virtud: su mediocridad es humildad, su debilidad es mansedumbre, su cobardía es temor de Dios. El esclavo construye otros mundos celestes dónde refugiarse tras la muerte porque odia esta vida. Para el débil el noble es, por lo tanto, el malvado que irá al infierno tras morir; esto muestra que el Resentimiento que los débiles no pueden proyectar en el mundo real, lo conciben tras la muerte porque el infierno nació del Resentimiento y el cielo de la cobardía hacia la vida.

Del resentimiento del débil nacieron las religiones que odian la vida, que propugnan Otro Mundo para despreciar este y convertirlo en un valle de lágrimas. Es con la religión y con su odio reconcentrado como surge la inteligencia, siendo su principal ejemplo la tradición judeo-cristiana. El débil reconcentrado en su Resentimiento calcula y alimenta una sucia llama interna que da lugar a lo que conocemos como inteligencia. La inteligencia, 
en efecto, en muchas ocasiones no es más que un profiláctico contra la espontaneidad de la vida, dirá Nietzsche.

La única manera de evitar el Resentimiento es vencer a otras voluntades. Por eso quien abraza la mística de la Voluntad de poder con plena conciencia de sus implicaciones, si no demuestra que es capaz de superar a todos los adversarios, no puede forjarse ilusiones de sí mismo. Pero la importancia que se le asigna a la victoria se puede apreciar cuando Nietzsche dice: "Ataco solo causas que son victoriosas (...) ataco solo causas contra las cuales no puedo encontrar aliados (...) ataco únicamente causas contra las cuales permaneceré sólo" (Nietzsche, 1980: 32). Solo la victoria sobre adversarios cada vez más fuertes es la verdadera medicina del espíritu humano.

Al igual que Girard, lo primero que nos podemos preguntar es qué ocurre si juzgamos a Nietzsche según sus propios criterios, ¿acaso, poseyó Nietzsche la fuerza interior que afirma de la Voluntad de poder? (Cfr. Girard, 1984: 82). Suponemos que Nietzsche debía creer que él era uno de los campeones invictos de la Voluntad de poder; después de todo, él la había descubierto. Pero la realidad era otra, pues hubo momentos en los que Nietzsche expresó sentirse incapaz de cumplir las exigencias de su propia mística. Esto se hace evidente cuando observamos que, en su relación con Wagner y con otros mediadores, Nietzsche no se sentía seguro en su identificación con Dionisos y, como Dionisos y la Voluntad de poder son una y la misma cosa entonces, ciertamente, no se sentía seguro de poseer aquella.

Lo segundo es que, al realizar una crítica radical comparando la mística de la Voluntad de poder con el proceso mimético, se nos revela que esta mística agrega realmente un esfuerzo hercúleo y sistemático para transformarse en Resentimiento, por cuanto los deseos son miméticos y, por fuerza, deben chocar con otros deseos; no porque decidan libremente hacerlo, sino porque están copiados los unos de los otros. Todos los deseos se declaran entre sí imitación y no imitación, casi simultáneamente, lo cual equivale a decir que los deseos recíprocamente frustrados se generan y se refuerzan unos a otros.

Se sabe que la Voluntad de poder es "la lucha constante y el antagonismo de todo existente individual contra todos los demás, (...) lo uno [que] intenta dominar a lo otro; (...) no es la tendencia a detenerse en una posición de poder ya conquistada, sino que es siempre voluntad de sobrepoder y de sobredominio" (Fink, 1984: 95). Se trata de una voluntad extremadamente fuerte, que busca sin desmayo adversarios aún más fuertes pero, en realidad, no encuentra ninguno. Con lo cual, la Voluntad de poder es un deseo frustrado y traumatizado que, como el Resentimiento, evoca la imagen de un obstáculo inamovible contra el cual choca el sentimiento inicial y al cual retorna 
obsesivamente solo para verse frustrado una y otra vez. En otras palabras, el Resentimiento es el propio reflejo de la Voluntad de poder, disfrazado de tal manera que ya no se puede reconocer a sí mismo.

Pero, como la victoria alcanzada no es el resultado de la lucha y el triunfo demostrado con la fuerza, sino de la indiferencia al tipo de desafío que representa esta mística, la propensión mimética se desata resolviéndose en la búsqueda del obstáculo insuperable, el cual se crea, si es necesario. Esto sugiere que la indiferencia misma puede llegar a ser el obstáculo más invencible. Por esto, para Nietzsche, el máximo mal es la indiferencia del mundo.

Este análisis de los efectos que Nietzsche atribuye al Resentimiento revela que estos, en realidad, corresponden a toda la Voluntad de poder. Nietzsche cree que podemos escapar a esos efectos si seguimos las reglas de la noble competición caballeresca, remover cielo y tierra para hallar al hombre que le enseñe la lección que merece. La verdad es que no corresponde con el genuino coraje ni con la verdadera adversidad, sino que esa búsqueda representa, en un estilo glorificado, las fases más avanzadas de mediación: el obstáculo insuperable. Por esto, la mística de la Voluntad de poder podría llamarse la ideología del deseo mimético o la religión del éxito. En pocas palabras, la Voluntad de poder es la ideología del mundo capitalista en que vivimos, no menos competitivo y agresivo en la esfera intelectual que en la esfera económica o política.

El problema es que este impulso competitivo y agresivo se puede caracterizar como una febril empresa de autodestrucción, que en el ámbito social conduce a la violencia generalizada y en el individuo a la locura. En el siguiente texto de Nietzsche se puede comprobar más directamente el aterrador proceso a nivel individual.

Haz que me vuelva loco, joh, divina potencia! Loco para que finalmente pueda creer en mí mismo. Dame delirio y convulsiones, momentos de lucidez y esa oscuridad que sobreviene repentinamente. Hazme estremecer de terror y dame ardores que ningún hombre mortal experimenta nunca: rodéame de rayos y fantasmas. Hazme dar alaridos, hazme aullar y arrastrarme como una bestia a cambio de fe en mí mismo. Me devora la duda sobre mí. He dado muerte a la ley y ahora siento por la ley el horror que siente el ser vivo ante un cadáver. A menos que no me encuentre por encima de la ley, soy el más réprobo de los réprobos. Un nuevo espíritu me posee; ¿de dónde procede ese espíritu si no procede de ti? Pruébame que te pertenezco ¡oh, divina potencia! Solamente la locura puede suministrar la prueba. (Nietzsche, 1994: I. 14) 
Girard comenta, "[A]quí se menciona la verdadera razón de esa oscilación entre lo maníaco y lo depresivo y es la falta de fe en sí mismo (...) Las dudas sobre sí mismo resultan de una comparación, no con algo, sino con alguien, [aunque] no se nombra en el texto". Ese alguien es el mediador, "es el verdadero centro alrededor del cual gira todo en la misma proporción en que el deseo del loco aspira a que todo gire alrededor de sí" (Girard, 1984: 87). Igualmente, menciona que la solución a esta falta de fe en sí mismo es más locura. El loco ya posee la locura y, sin embargo, desea más para lograr la certeza, en la vieja creencia romántica de la locura como signo de elección, como prueba de afinidad con divinas potencias. Pero la verdad es que la locura es duda, y una locura más extrema significa cada vez más duda, más oscilaciones, altibajos tan extremos y violentos que todo el mecanismo pendular se derrumba. Solo entonces la oscilación de Dionisos entre Nietzsche y el mediador quedaría interrumpida para siempre. Solo entonces quedaría eliminada la falta de fe en sí mismo. Como dice Girard: "La única certeza y estabilidad que el loco puede considerar es la destrucción de su mente, el triunfo de la locura, equivocadamente representada como el triunfo del sujeto" (Girard, 1984: 88).

En realidad, tenemos el colapso del pensamiento de Nietzsche porque es la etapa del deseo donde no hay objeto alguno; no hay más que el double bind mimético, la obsesión del modelo-obstáculo que empuja, si no hay un mecanismo que lo reduzca a la razón o engendre esa razón, hacia la locura y la muerte. Pero la demencia de Nietzsche, y de muchos otros, tiene sus raíces en una experiencia que no es realmente ajena a ninguno de nosotros, pues el principio de mediación se dirige al centro mismo de la motivación individual en el campo cultural. Para entenderlo no debemos abordar temas como Dionisos o la Voluntad de poder en su estado final metafísico, porque es el resultado de un proceso que debe considerarse en su totalidad y que comienza en una clave diferente. Al principio, la imitación y la rivalidad están ya presentes en el mundo intelectual pero aún tienen un objeto reconocible, un objeto por el que vale la pena luchar, y que se podría determinar como la omnipotencia intelectual y artística. Ya a mediados del siglo XVIII, el prestigio de los intelectuales hace que el juicio de estos sea más importante para los otros intelectuales que la opinión de los aristócratas benefactores. En este microambiente, las relaciones más importantes no son entre superiores e inferiores sociales, sino entre pares, aun cuando rara vez sean experimentadas como relaciones de igualdad porque el juicio encubierto de los pares, a falta de criterios objetivos, desempeña un papel decisivo. Este estado de cosas no deja de engendrar una gran cantidad de alucinaciones, como resultado de la más insignificante oposición exterior en la que la violencia más o menos oculta de estas relaciones no cesa de influir en la creación intelectual (véase Girard, 1984: 91). 
Las presiones del mundo en general son reales pero están filtradas y deformadas por el microambiente del mundo intelectual, que constituye una red de complejas e inestables relaciones regidas por el deseo engendrado por mediación, donde el otro se convierte en figura fascinante alrededor del cual girará constantemente porque representa un obstáculo real o imaginario. Lo importante aquí es, primero, la alternancia regular entre una imaginaria omnipotencia del yo en la soledad y la omnipotencia real de los otros en la sociedad y, segundo, que el otro es el obstáculo mimético en su quintaesencia.

Sin embargo, la causa de la falta de fe, sugerida por el aforismo, es haber matado a la ley. La ley es asesinada por el propio loco y su cadáver se considera responsable de todo el desastre que ocurre. Esa acusación es falsa, desde luego, por cuanto la ley no está presente para impedir lo que ocurre después de su muerte, es decir, para impedir el proceso mimético. La verdad es que mientras la ley está viva existe la diferencia que separa a los dobles potenciales canalizando el deseo mimético hacia metas comunes, que no son divisorias de la comunidad.

La acusación a la ley de ser responsable de todo el desastre es fruto del deseo mismo que se niega a afrontar su propia verdad. Y es también una última protección contra la revelación plena de la verdad, una revelación que significa el fin de toda paz y salud. La acusación a la ley es la solución que nos legó una época liderada por Nietzsche, Freud y Marx: acabar con la ley moral, la ley psíquica, con la ley en cualquier sentido. El cadáver de la ley es el último objeto de sacrificio, la última diferencia que aún difiere un poco el encuentro frente a frente de los dobles.

Solo me queda decir, a manera de conclusión:

1- La teoría mimética se ha convertido en una abierta y fuerte crítica a la más cara de nuestras ilusiones, encontrada en ciertos planteamientos que se han vuelto comunes en nuestra época, a saber: la íntima convicción de que nuestros deseos son realmente nuestros, de que son verdaderamente originales y espontáneos. Por lo que cabe imaginar que el malestar y la desdicha provienen de las trabas puestas al deseo por los tabúes religiosos, culturales, judiciales que, una vez derribados, la maravillosa inocencia del deseo daría sus frutos. Es evidente, entonces, nuestra resistencia a reconocer la verdadera fuente de nuestros deseos.

2- A medida que el deseo elimina los obstáculos exteriores, dispuestos por la sociedad para prevenir su contagio, el obstáculo estructural suscitado por las interferencias miméticas, el modelo metamorfoseado en rival sustituye a la prohibición caída. Cuanto más se imaginan los hombres que realizan sus utopías del deseo, más trabajan por el perfeccionamiento de ese 
mundo competitivo que nos ahoga. Apenas se borran los últimos tabúes, innumerables intelectuales comienzan a hablar de ellos como si fueran más pesados, o los sustituyen por un poder omnipresente y omnisciente, lo cual bien se podría denominar como una nueva traducción mítica de las estrategias miméticas.

3- Nuestra sociedad ha mostrado ser capaz de desencadenar el deseo mimético sin temer que el sistema se desboque irremediablemente, pero el precio a pagar es el reforzamiento de las tensiones competitivas, ligada a la democratización y vulgarización de la neurosis. En los ambientes dominados por la fiebre de la competencia y las ansias de méritos, como en el mundo de los negocios, o en un contexto de ociosidad relativa, como en el mundo de los intelectuales, favorable a la observación recíproca, la ciclotimia se alimenta de signos no ilusorios ni insignificantes. El espíritu de competencia depende de comparaciones que no son seguras porque no existe punto fijo de comparación. Día tras día hay menos medida para controlar las amplificaciones emocionales en una sociedad cada vez más desestructurada y, por tanto, más amenazada por las oscilaciones miméticas, en especial, en las actividades o vocaciones que dependen directamente del juicio de los demás, como las de los políticos, los actores, los escritores.

La pregunta es si no habrá una amenaza de psicosis, de paranoia o de miedo al otro siempre que la intuición individual en estas materias supera cierto umbral. 


\section{Referencias}

Bateson, G. (1972). Toward a Theory of Schizophrenia, Minimal Requirements for a Theory of Schizophrenia and Double Bind. Steps to an Ecology of Mind. Chicago: The University of Chicago Press.

FINK, E. (1984). La filosofia de Nietzsche. Madrid: Alianza editorial.

GIRARD, R. (1984). Literatura, mímesis y antropología. Barcelona: Gedisa.

GIRARD, R. (1982). El misterio de nuestro mundo. Salamanca: Sígueme.

GIRARD, R. (1976). Superman in the Underground: Strategies of MadnessNietzsche, Wagner, and Dostoyevski. MLN. Vol. 91, No. 6. (pp. 1161-1185)

Golsan, R. (2002). René Girard and Myth: An Introduction. New York and London: Routledge.

Grande, P. (2009). Mimesis and Desire. An Analysis of the Religious Nature of Mimesis and Desire in the Work of René Girard. U.S.A.: Lap Lambert.

HeidegGer, M. (2000). Nietzsche. Barcelona: Destino.

Kaufmann, W.A. (1956). Nietzsche Philosopher, Psychologist, Antichrist. New York: Meridian Books.

Kirwan, M. (2005). Discovering Girard. Cambridge: Cowley.

Nietzsche, F. (1994). Aurora. Madrid: M. E. Editores, S. L.

NIeTZsChe, F. (1983). Así habló Zaratustra. Madrid: Alianza editorial.

Nietzsche, F. (1980). Ecce Homo. Madrid: Alianza editorial. 